Wk24 in GUS-treated pts, with separation from PBO observed as early as Wk8; improvements were maintained at Wk52. At Wk24, BASDAI 50 response rates were higher in the Q4W and Q8W groups vs PBO (38\% and $40 \%$ vs $19 \%) .{ }^{1}$ At WK52, mean BASDAI component scores for PBO pts who crossed over to GUS Q4W at Wk24 were similar to those for pts who were randomized to GUS. ${ }^{2}$ A similar trend was observed for BASDAI50 response.

Conclusion: Among PsA pts with axial symptoms and sacroiliitis (via investigator-confirmed imaging) in the DISCOVER-1\&2 trials, GUS treatment resulted in lower mean scores for all six BASDAI components compared with PBO as early as Wk 8 and through Wk24, with mean scores maintained at Wk52. REFERENCES:

[1] Helliwell P, et al. Ann Rheum Dis. 2020; 79; Suppl 1.

[2] Mease PJ, et al. Arthritis Rheumatol. 2020; 72 (suppl 10).

Table 1. Baseline demographic and disease characteristics for patients who were identified by physicians as having symptoms consistent with spondylitis and had sacroiliitis confirmed via prior radiograph/MRI or screening radiograph

\begin{tabular}{lccc}
\hline & GUS Q4W & GUS Q8W & Placebo \\
\hline Patients, $\mathrm{n}$ & 103 & 91 & 118 \\
Male, $\mathrm{n}(\%)$ & $68(66)$ & $54(59)$ & $69(59)$ \\
Age, years & $44.9 \pm 11.8$ & $45.0 \pm 10.7$ & $45.3 \pm 11.0$ \\
BASDAl & 95 & & \\
Patients, $\mathrm{n}$ & $6.4 \pm 1.7$ & $6.5 \pm 1.8$ & $6.6 \pm 1.5$ \\
Score & & & \\
BASDAI Components & $6.4 \pm 2.0$ & $6.7 \pm 1.9$ & $6.5 \pm 1.9$ \\
Fatigue & $6.6 \pm 2.1$ & $6.5 \pm 2.3$ & $6.7 \pm 2.0$ \\
Spinal pain & $6.3 \pm 1.9$ & $6.5 \pm 2.2$ & $6.8 \pm 1.7$ \\
Joint pain & $6.3 \pm 2.1$ & $6.4 \pm 2.2$ & $6.3 \pm 2.2$ \\
Enthesitis & $6.8 \pm 2.1$ & $6.7 \pm 2.5$ & $7.0 \pm 2.0$ \\
Qualitative morning stiffness & $6.2 \pm 2.9$ & $5.7 \pm 2.9$ & $6.1 \pm 2.8$ \\
Quantitative morning stiffness & & \\
\hline
\end{tabular}

Data are mean \pm standard deviation unless otherwise noted.BASDAl, Bath ankylosing spondylitis disease activity index

Figure. Mean scores of BASDAI components at week 24, DISCOVER-1 and DISCOVER-2

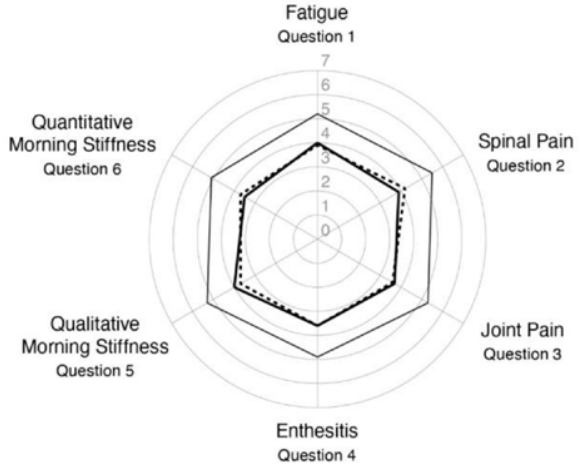

- PBO .... GUS $100 \mathrm{mg}$ Q4W — GUS $100 \mathrm{mg}$ Q8W

Disclosure of Interests: Frank Behrens Speakers bureau: AbbVie, Boehringer Ingelheim, Bristol Myers Squibb, Celgene, Chugai, Eli Lilly, Galapagos, Genzyme, Gilead, Janssen, MSD, Novartis, Pfizer, Roche, Sanofi, and UCB, Consultant of: AbbVie, Boehringer Ingelheim, Bristol Myers Squibb, Celgene, Chugai, Eli Lilly, Galapagos, Genzyme, Gilead, Janssen, MSD, Novartis, Pfizer, Roche, Sanofi, and UCB, Grant/research support from: Celgene, Chugai, Janssen, Pfizer, and Roche, Philip J Mease Consultant of: AbbVie, Amgen, Boehringer Ingelheim, Bristol Myers Squibb, Eli Lilly, Galapagos, Gilead, GlaxoSmithKline, Janssen, Novartis, Pfizer, SUN, and UCB, Grant/research support from: AbbVie, Amgen, Bristol Myers Squibb, Eli Lilly, Galapagos, Gilead, Janssen, Novartis, Pfizer, SUN, and UCB, Philip Helliwell Consultant of: Galapagos, Janssen, Novartis, Grant/research support from: AbbVie, Janssen, Pfizer, May Shawi Shareholder of: Johnson \& Johnson, Employee of: Janssen Global Services, Wim Noel Shareholder of: Johnson \& Johnson, Employee of: Janssen Scientific Affairs, Soumya D Chakravarty Shareholder of: Johnson \& Johnson, Employee of: Janssen Scientific Affairs, Alexa Kollmeier Shareholder of: Johnson \& Johnson, Employee of: Janssen Research \& Development, Xie L Xu Shareholder of: Johnson \& Johnson, Employee of: Janssen Research \& Development, Stephen Xu Shareholder of: Johnson \& Johnson, Employee of: Janssen Research \& Development, Yanli Wang Employee of: IQVIA providing statistical support (funded by Janssen), Xenofon Baraliakos Consultant of: AbbVie, Amgen, Bristol Myers Squibb, Eli Lilly, Galapagos, Gilead, Janssen, Novartis, Pfizer, and UCB,
Grant/research support from: AbbVie, Amgen, Bristol Myers Squibb, Eli Lilly, Galapagos, Gilead, Janssen, Novartis, Pfizer, and UCB.

DOI: 10.1136/annrheumdis-2021-eular.398

\section{AB0525 GUSELKUMAB TREATMENT SHOWS RAPID ONSET OF EFFECT ON COMPONENTS OF AMERICAN COLLEGE OF RHEUMATOLOGY RESPONSE CRITERIA: RESULTS OF 2 RANDOMIZED PHASE 3 TRIALS}

P. Nash ${ }^{1}$, I. Mclnnes ${ }^{2}$, C. T. Ritchlin ${ }^{3}$, W. C. Tsai ${ }^{4}$, Y. Y. Leung ${ }^{5}$, L. S. Tam ${ }^{6}$, D. Furtner ${ }^{7}$, M. Shawi ${ }^{8}$, S. Xu ${ }^{9}$, S. Sheng ${ }^{9}$, A. Kollmeier ${ }^{10}$, A. Deodhar ${ }^{11}$. ${ }^{1}$ Griffiths University and University of Queensland, Rheumatology Research Unit, Maroochydore, Australia; ${ }^{2}$ University of Glasgow, Institute of Infection, Immunity and Inflammation, Glasgow, United Kingdom; ${ }^{3}$ University of Rochester Medical Center, Department of Medicine, Allergy/Immunology and Rheumatology, Rochester, United States of America; ${ }^{4}$ Kaohsiung Medical University, Division of Allergy, Immunology and Rheumatology, Kaohsiung City, Taiwan, Republic of China; ${ }^{5}$ Singapore General Hospital, Duke -NUS Medical School, Rheumatology \& Immunology, Singapore, Singapore; ${ }^{6}$ The Chinese University of Hong Kong, Department of Medicine \& Therapeutics, Shatin, Hong Kong (SAR); ${ }^{7}$ Janssen, a division of Johnson \& Johnson Pte. Ltd, Immunology, Singapore, Singapore; ${ }^{8}$ Janssen Scientific Affairs, LLC, Immunology, Spring House, United States of America; ${ }^{9}$ Janssen Research \& Development, LLC, Biostatistics, Spring House, PA, United States of America; ${ }^{10}$ Janssen Research \& Development, LLC, Immunology, San Diego, CA, United States of America; ${ }^{11}$ Oregon Health \& Science University, Division of Arthritis \& Rheumatic Diseases, Oregon, United States of America

Background: Guselkumab (GUS), an anti-interleukin-23p19-subunit monoclonal antibody, demonstrated efficacy vs placebo (PBO) in achieving American College of Rheumatology $20 \%$ improvement (ACR20) response in patients (pts) with active psoriatic arthritis (PsA) in two phase 3 trials, DISCOVER-1 \& 2.,

Objectives: To assess the differential treatment effects of GUS across individual components of ACR response in PsA pts participating in the DISCOVER-1 \& 2 trials.

Methods: In DISCOVER-1 \& 2, 1120 pts were randomized \& treated with GUS $100 \mathrm{mg}$ every 4 weeks (Q4W; N=373); GUS $100 \mathrm{mg}$ at Week (W)0 and W4, then Q8W $(\mathrm{N}=375)$; or matching PBO $(\mathrm{N}=372)$. Pts were evaluated by independent joint assessors at study visits. ACR20 response is defined as $\geq 20 \%$ improvement from baseline in both tender joint count (0-68 [TJC68]) and swollen joint count (0-66 [SJC66]) and $\geq 20 \%$ improvement from baseline in $\geq 3$ of 5 assessments: Patient Assessment of Pain [Pt Pain], Patient Assessment of Global Disease Activity (arthritis) [PtGA], Physician Assessment of Global Disease Activity [PGA], Patient assessment of physical function as measured by Disability Index of the Health Assessment Questionnaire (HAQ-DI), and C-reactive protein (CRP). For each ACR component, achievement of $\geq 20 \%$ improvement from baseline was assessed over time through W24 for the combined (Q4W+Q8W) GUS groups, and median time to onset of treatment effect was determined with Kaplan-Meier curves by randomized group.

Results: Median time to response for all components except SJC66 occurred earlier with GUS than PBO. Time to onset of ACR20 treatment effect is shown in Figure 1. CRP data show $56 \%$ of GUS-treated pts had diminution of systemic inflammation by W4 (Table 1). Reduction in systemic inflammation was accompanied or rapidly followed by GUS-related improvement in both PtGA and PGA (median W4-8). Although SJC66/TJC68 data showed similar patterns, there was also a high $\mathrm{PBO}$ response (data not shown). Consistent with early reductions in systemic inflammation, $48-61 \%$ of GUS-treated pts had $\geq 20 \%$ improvement in TJC68/SJC66/PGA at W4 (Table 1), and $45-48 \%$ had $\geq 20 \%$ improvement in HAQ-DI, PtGA, and Pt Pain by W8. By W24, $>80 \%$ of GUS-treated pts had $\geq 20 \%$ improvement in SJC66/TJC68/PGA, followed by 63-64\% with this degree of improvement in PtGA, CRP, and Pt Pain, and 57\% for HAQ-DI.

Conclusion: GUS demonstrated ACR20 improvements with separation from $\mathrm{PBO}$ in $\mathrm{ACR}$ components as early as W4, which is consistent with reduced inflammation by GUS and prior serological studies. ${ }^{3}$ At early study time points, both pts and physicians were able to discern improvements in signs and symptoms of arthritis that rapidly followed reductions in systemic inflammation (CRP). The predominant drivers of ACR20 response rates at W24 in GUS pts were SJC66/TJC68/PGA

\section{REFERENCES:}

[1] Deodhar A et al. Lancet. 2020;395:1115-25

[2] Mease P et al. Lancet. 2020;395:1126-36

[3] Siebert S et al. EULAR 2020. Presentation OP0229 
Table 1.

\begin{tabular}{lcccccc}
\hline & W4 & W8 & W12 & W16 & W20 & W24 \\
\hline ACR20 & 20 & 39 & 50 & 56 & 60 & 61 \\
HAQ-DI score & 36 & 45 & 52 & 54 & 56 & 57 \\
SJC66 & 61 & 74 & $\mathbf{8 4}$ & $\mathbf{8 6}$ & $\mathbf{8 7}$ & $\mathbf{8 8}$ \\
TJC68 & 48 & 65 & 75 & 79 & $\mathbf{8 0}$ & $\mathbf{8 1}$ \\
PGA & 50 & 67 & 74 & 78 & $\mathbf{8 1}$ & $\mathbf{8 1}$ \\
PtGA & 35 & 48 & 58 & 59 & 62 & 64 \\
Pt Pain & 32 & 48 & 55 & 58 & 61 & 63 \\
CRP & 56 & 60 & 62 & 63 & 64 & 64 \\
\hline
\end{tabular}

Figure. Median time to ACR20 response.

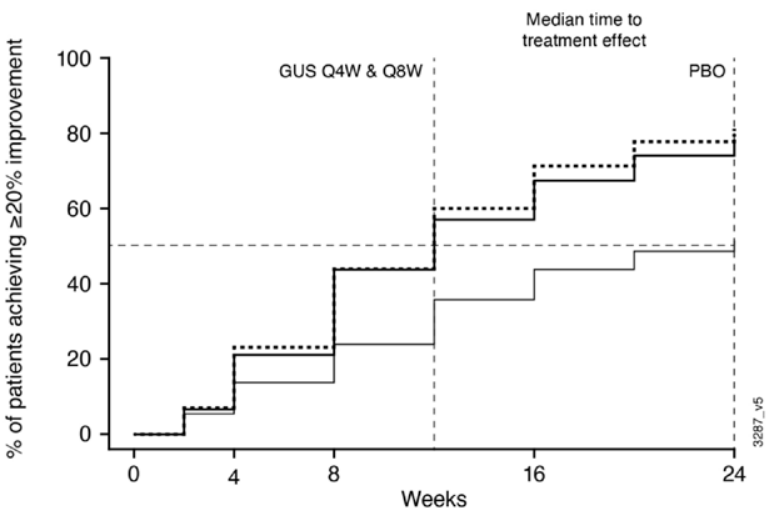

$\begin{array}{rrrrcr}\text { N } & & & & \\ \text { GUS Q4W } & 373 & 347 & 287 & 149 & 83 \\ \text { GUS Q8W } & 375 & 350 & 296 & 161 & 97 \\ \text { PBO } & 372 & 352 & 321 & 239 & 191 \\ & & & & & \\ \ldots . . . . . & \text { GUS 100 mg Q4W } & & \end{array}$

Data shown at W2 were derived solely from DISCOVER-2, as DISCOVER-1 did not include assessments at W2. The intersection of horizontal and vertical dashed lines denotes the time at which $50 \%$ of patients in a treatmen group achieved ACR20 response.

Figure 1

Disclosure of Interests: Peter Nash Consultant of: AbbVie, Bristol Myers Squibb, Boehringer, Celgene, Gilead, Eli Lilly, Janssen, Novartis, Pfizer, Roche, Sandoz, Sun, Grant/research support from: AbbVie, Bristol Myers Squibb, Boehringer, Celgene, Gilead, Eli Lilly, Janssen, Novartis, Pfizer, Roche, Sandoz, Sun, lain McInnes Consultant of: AbbVie, Bristol-Myers Squibb, Celgene, Eli Lilly and Company, Gilead, Janssen, Novartis, Pfizer, and UCB, Grant/research support from: Bristol-Myers Squibb, Celgene, Eli Lilly and Company, Janssen, and UCB, Christopher T. Ritchlin Consultant of: AbbVie, Amgen, Janssen, Eli Lilly, Gilead, Novartis, Pfizer, and UCB, Grant/research support from: AbbVie, Amgen, and UCB, Wen-Chan Tsai Consultant of: AbbVie, Eli Lilly, Janssen, Pfizer, and Novartis, Ying Ying Leung Consultant of: Abbvie, Eli Lilly, Janssen, and Novartis, Lai-Shan Tam Consultant of: AbbVie, Boehringer Ingelheim, Janssen, Lilly, Pfizer, and Sanofi, Grant/research support from: Amgen, Boehringer Ingelheim, Janssen, GSK, Novartis, and Pfizer, Daniel Furtner Employee of: Janssen, a division of Johnson \& Johnson Pte. Ltd., May Shawi Employee of: Janssen Research and Development, LLC, Stephen Xu Employee of: Janssen Research and Development LLC, Shihong Sheng Employee of: Janssen Research and Development, LLC, Alexa Kollmeier Employee of: Janssen Research and Development, LLC, Atul Deodhar Speakers bureau: AbbVie, Eli Lilly, Janssen, Novartis, Pfizer, and UCB, Consultant of: AbbVie, Amgen, Boehringer Ingelheim, Bristol Myers Squibb, Celgene, Eli Lilly, Galapagos, GlaxoSmithKline, Janssen, Novartis, Pfizer, and UCB, Grant/research support from: AbbVie, Eli Lilly, GlaxoSmithKline, Novartis, Pfizer, and UCB. DOI: 10.1136/annrheumdis-2021-eular.434

\begin{tabular}{|l|l}
\hline AB0526 & SUSTAINED GUSELKUMAB RESPONSE IN PATIENTS \\
WITH ACTIVE PSORIATIC ARTHRITIS REGARDLESS \\
OF BASELINE DEMOGRAPHIC AND DISEASE \\
CHARACTERISTICS: POOLED RESULTS THROUGH \\
WEEK 52 OF TWO PHASE 3, RANDOMIZED, PLACEBO- \\
CONTROLLED STUDIES
\end{tabular}

C. T. Ritchlin ${ }^{1}$, P. J. Mease ${ }^{2}$, W. H. Boehncke ${ }^{3}$, J. Tesser ${ }^{4}$, E. Schiopu ${ }^{5}$, S. D. Chakravarty ${ }^{6,7}$, A. Kollmeier ${ }^{8}$, E. C. Hsia ${ }^{8,9}$, X. L. $\mathrm{Xu}^{8}$, M. Shawi $^{10}$,
Y. Jiang ${ }^{11}$, S. Sheng ${ }^{11}$, J. F. Merola ${ }^{12}$, I. Mclnnes $^{13}$, A. Deodhar ${ }^{14}$ ${ }^{1}$ University of Rochester Medical Center, Rochester, Department of Medicine - Allergy/lmmunology and Rheumatology, Rochester, United States of America; ${ }^{2}$ Swedish Medical Center/Providence St. Joseph Health and University of Washington, Rheumatology Research, Seattle, United States of America; ${ }^{3}$ Geneva University Hospitals, Dermatology, Geneva, Switzerland; ${ }^{4}$ Arizona Arthritis and Rheumatology Associates, Rheumatology, Phoenix, United States of America; ${ }^{5}$ Michigan Medicine Rheumatology Clinic, Rheumatology \& Internal Medicine, Ann Arbor, United States of America; ${ }^{6}$ Janssen Scientific Affairs, LLC, Immunology, Horsham, United States of America; ${ }^{7}$ Drexel University College of Medicine, Rheumatology, Philadelphia, United States of America; ${ }^{8}$ Janssen Research \& Development, LLC, Immunology, Spring House, United States of America; ${ }^{9}$ University of Pennsylvania Medical Center, Rheumatology, Philadelphia, United States of America; ${ }^{10}$ Janssen Global Services, LLC, Immunology, Horsham, United States of America; ${ }^{11}$ Janssen Research \& Development, LLC, Biostatistics, Spring House, United States of America; ${ }^{12}$ Brigham and Women's Hospital, Harvard Medical School, Department of Dermatology, and Department of Medicine, Division of Rheumatology and Immunology, Boston, United States of America; ${ }^{13}$ University of Glasgow, Institute of Infection, Immunity and Inflammation, Glasgow, United Kingdom; ${ }^{14}$ Oregon Health \& Science University, Division of Arthritis and Rheumatic Diseases, Portland, United States of America

Background: In the Phase 3 DISCOVER- $1^{1}$ \& DISCOVER- $2^{2}$ trials, guselkumab (GUS), a human monoclonal antibody targeting the IL-23p19-subunit, was effective in psoriatic arthritis (PsA) across joint \& skin endpoints. At Week 24 (W24), GUS benefit was consistent regardless of baseline $(\mathrm{BL})$ demographic \& disease characteristics. $^{3}$

Objectives: We assessed whether GUS efficacy was sustained through W52 in pooled DISCOVER-1 \& -2 patients (pts) across select BL subgroups.

Methods: Adults with active PsA despite standard therapies were enrolled in DISCOVER-1 (swollen [SJC] $\geq 3$ \& tender joint count [TJC] $\geq 3$, C-reactive protein $[\mathrm{CRP}] \geq 0.3 \mathrm{mg} / \mathrm{dL}$ ) \& DISCOVER-2 (SJC $\geq 5 \& T J C \geq 5$, CRP $\geq 0.6 \mathrm{mg} / \mathrm{dL}$ ). $31 \%$ of DISCOVER-1 pts had received $1-2$ prior tumor necrosis factor inhibitors; DISCOVER-2 pts were biologic naïve. Pts were randomized 1:1:1 to GUS $100 \mathrm{mg}$ every 4 weeks (Q4W); GUS $100 \mathrm{mg}$ at W0, W4, then Q8W; or placebo (PBO). Pts randomized to PBO received GUS $100 \mathrm{mg} \mathrm{Q4W} \mathrm{starting} \mathrm{at} \mathrm{W24} \mathrm{\&} \mathrm{were} \mathrm{excluded} \mathrm{from} \mathrm{these} \mathrm{analyses}$ assessing maintenance of effect from W24 to W52. GUS effects on joint (American College of Rheumatology [ACR]20/50/70) \& skin (Investigator's Global Assessment [IGA=0/1 + $\geq 2$-grade reduction from W0] in pts with $\geq 3 \%$ body surface area [BSA] with psoriasis \& IGA $\geq 2$ at W0) endpoints were evaluated by pt BL SJC, TJC, conventional synthetic disease-modifying antirheumatic drug (csDMARD) use, body mass index (BMI), PsA duration, \& \% BSA with psoriasis. Missing data were imputed as nonresponse through W52.

Results: BL pt characteristics in DISCOVER-1 ( $\mathrm{N}=381)$ \& DISCOVER-2 $(\mathrm{N}=739)$ were well balanced across randomized groups. ${ }^{1,2}$ Among 1120 pooled pts, mean SJC was 11 , mean TJC was 21 , \& $68 \%$ used csDMARDs (primarily methotrexate [MTX]). At W24, 62\% (232/373) \& 60\% (225/375), respectively, of GUS Q4W- \& Q8W-treated pts achieved ACR20 vs $29 \%$ (109/372) of PBO, with GUS effect consistently observed across pt BL subgroups (Figure 1). ACR20 response rates were sustained or increased at W52 in the GUS Q4W (72\%) \& Q8W (70\%) groups \& across SJC (61$79 \%)$, TJC (68-76\%), \& csDMARD use (68-80\%) subgroups (Table 1) \& pt subgroups defined by BL BMI, PsA duration, \& \% BSA with psoriasis (data not shown). ACR50 \& 70 response patterns were similar to ACR20 (Table 1). In pts with $\geq 3 \%$ BSA psoriasis \& IGA $\geq 2$ at BL, $71 \%(193 / 273)$ \& 66\% (171/258) of GUS Q4W- \& Q8W-treated pts, respectively, vs $18 \%$ (47/261) of PBO, achieved IGA 0/1 at W24, with GUS effect consistently observed across pt BL subgroups (Figure 1). IGA 0/1 response rates were also sustained or increased at W52 in the GUS Q4W (80\%) \& Q8W $(71 \%)$ groups \& across \% BSA with psoriasis (67-87\%) \& csDMARD use (68-87\%) subgroups (Table 1) \& pt subgroups defined by BL BMI and PsA duration (data not shown).

Conclusion: Treatment with GUS $100 \mathrm{mg}$ Q4W \& Q8W resulted in sustained improvement in signs \& symptoms of active PsA through W52 regardless of pt BL characteristics.

\section{REFERENCES:}

[1] Deodhar A, et al. Lancet 2020;395:1115-25;

[2] Mease P, et al. Lancet 2020;395:1126-36;

[3] Deodhar A, et al. American College of Rheumatology 2020; Poster P0908. 